\title{
Application of high strength reinforcing bars in earthquake-resistant structure elements
}

\author{
Kurniawan Setiadi Kamaruddin ${ }^{1, *}$, Iswandi Imran $^{2}$, Maulana Derry Imansyah ${ }^{1}$, \\ Muhammad Riyansyah ${ }^{2}$, and Aris Ariyanto ${ }^{2}$ \\ ${ }^{1}$ Post Graduate Program, Civil Engineering Department, Institut Teknologi Bandung, Indonesia \\ ${ }^{2}$ Structure Research Group, Civil Engineering Department, Institut Teknologi Bandung, Indonesia
}

\begin{abstract}
Currently, design of reinforced concrete buildings is still dominated with normal strength reinforcing bars, not exceeding $420 \mathrm{MPa}$ yield strength. Meanwhile, the use of higher strength reinforcing bars tend to increase due to some benefits in the construction, such as reducing the total weight of reinforcing bars and alleviating reinforcing bars congestions. In this study, reinforcing bars with yield strength of $520 \mathrm{MPa}$ are utilized in the reinforced concrete beam-column joint. The objective is to study the seismic performance of reinforced concrete beam-column joints. A total of 3 interior beam-column joints, half-scaled specimens with different yield strengths and bar diameters was tested. One of the test specimens which was $16 \mathrm{~mm}$ diameter and had normal strength reinforcing bar. The other two specimens use high strength reinforcing bars, and have $16 \mathrm{~mm}$ and $19 \mathrm{~mm}$ diameter bars. Loading protocol of all the specimens is conformed with ACI 374.2. Dissipation energy and deformability of the joints is then compared. Normalized energy dissipation of the specimens with high strength reinforcing bars was slightly lower than that of the specimens with normal reinforcing bars. However, specimens with high strength reinforcing bars tend to have smaller deformability than that of the specimens with normal reinforcing bars.
\end{abstract}

Keywords: cyclic loading, high-strength reinforcing steel, beam-column joint

\section{Introduction}

Currently, the design of earthquake-resistant reinforced concrete buildings is still dominated with normal strength reinforcing bars, not exceeding $420 \mathrm{MPa}$ yield strength. The use of high strength reinforcing bars provide several advantages, it can not only reduce the amount of reinforcing steel in the structure, saves material, delivery and placement costs, but also helps eliminate reinforcing bars congestions. That will increase the workmanship, durability, and shorten construction time. The major problem in the use of high strength reinforcing steel bars is that high-strength reinforcing bars tend to have smaller bond and ductility than that of normal strength reinforcing bars $[1,2]$. The objective of the present research was to study the use of high strength reinforcement steel bars by comparing the post-elastic behavior between

\footnotetext{
* Corresponding author: kurniawansetiadi72@gmail.com
} 
reinforced concrete $(\mathrm{R} / \mathrm{C})$ with conventional reinforcing steel bar and $\mathrm{R} / \mathrm{C}$ with high strength reinforcing steel bars.

\section{Experimental method}

In this experiment, 3 half-scale interior beam-column joint specimens made from $\mathrm{R} / \mathrm{C}$ with normal (D16-400N) and high strength reinforcing bars (D16-500N and D19-500N) were tested with cyclic lateral loads in order to study their seismic performance. The analysis of the performance included strength, realtive energy dissipation ratio, hysteretic curve gradient of load-deflection, ductility, energy dissipation, and stiffness degradation. The loading protocol is according to ACI 3.74-2 [3].

\subsection{Material properties of specimens}

All specimens used conventional concrete with fc' 30 MPa. One of the specimens, D16$400 \mathrm{~N}$, use normal reinforcing bar with fy $420 \mathrm{MPa}$, and the two other specimens, D16-500N and D19-500N, use high strength reinforcing bars with fy $520 \mathrm{MPa}$. Specimen D16-400N is used as a control specimen. Reinforcement bars in this experiment was used according to ASTM A615 [4] and SNI 2052 [5]. Material used for each specimen is given in Table 1.

Table 1. Material properties.

\begin{tabular}{|c|c|c|c|c|}
\hline \multirow[b]{2}{*}{ Number } & \multirow[b]{2}{*}{ Specimen } & \multicolumn{2}{|c|}{ Longitudinal Reinforcement } & \multirow{2}{*}{$\begin{array}{c}\text { Compressive } \\
\text { Strength } \\
\text { (MPa) }\end{array}$} \\
\hline & & $\begin{array}{c}\text { Yield Str. } \\
\text { (MPa) }\end{array}$ & $\begin{array}{c}\text { Diameter } \\
(\mathrm{mm})\end{array}$ & \\
\hline 1 & D16-400N & 420 & 16 & 30 \\
\hline 2 & D16-500N & 520 & 16 & 30 \\
\hline 3 & D19-500N & 520 & 19 & 30 \\
\hline
\end{tabular}

Mechanical properties of each material are shown in Table 2. The mechanical properties of reinforcing bars were obtained from the tensile strength test of 2 sets of specimens for each yield strength (i.e. $420 \mathrm{MPa}$ and $520 \mathrm{MPa}$ ), consisted of 4 specimens each. The tensile test was conducted according to ASTM A370. A compressive strength test of concrete material was carried out at 7,14, and 28 days, consisting of 2 cylinders $(15 \times 30 \mathrm{~mm})$ each.

Table 2. Mechanical properties of specimens.

\begin{tabular}{|c|c|c|c|c|c|}
\hline \multirow[b]{2}{*}{ Material } & \multicolumn{4}{|c|}{ Reinforcing Bars } & \multirow[b]{2}{*}{$\begin{array}{c}\text { Compressive } \\
\text { Str. (MPa) }\end{array}$} \\
\hline & $\begin{array}{c}\text { Sectional } \\
\text { Area } \\
\left(\mathrm{mm}^{2}\right)\end{array}$ & $\begin{array}{c}\text { Yield } \\
\text { Str. } \\
\text { (MPa) }\end{array}$ & $\begin{array}{l}\text { Tensile Str. } \\
\text { (MPa) }\end{array}$ & $\begin{array}{c}\text { Young } \\
\text { Modulus } \\
\text { (GPa) }\end{array}$ & \\
\hline D16-400N & 201.06 & 434.1 & 577.4 & 198.1 & 31.0 \\
\hline D16-500N & 201.06 & 485.2 & 630.9 & 207.9 & 32.7 \\
\hline D19-500N & 283.53 & 503.9 & 674.9 & 195.7 & 31.7 \\
\hline
\end{tabular}

\subsection{Design of the specimens}

All specimens have a $350 \times 350 \mathrm{~mm}$ column and $150 \times 250 \mathrm{~mm}$ beam. The column was reinforced by 8 longitudinal bars, with different diameters as stated in Table 1 . All specimens were designed according to SNI 2847 Chapter 21 [6]. The reinforcement ratio of the columns was $1.31 \%$ for specimens with D16 bars, and $1.85 \%$ for specimens with D19 bars. For confinement and shear reinforcement, all of the specimens used D10 bars with $80 \mathrm{~mm}$ spacing. 
For specimens with D16 reinforcing bars, different amount of reinforcing bars was used as top and bottom longitudinal reinforcement of the beams. The top layer of the section was reinforced by $3-\mathrm{D} 16$ bars or $1.6 \%$ reinforcement ratio, while the bottom layer was reinforced by 2 -D16 bars with $1.1 \%$ reinforcement ratio. While for the D19 specimen, longitudinal reinforcing bars were symmetrical between the top and bottom layer with 2-D19 bars or $1.51 \%$ reinforcement ratio. High over strength ratio of specimen's column and beam component, with magnitude ranging from 2-3 was used in order to ensure that all specimens end up with failure of both beams rather than the column failure or to satisfy the strongcolumn weak-beam requirements.

All of the specimens used D10 bars with $55 \mathrm{~mm}$ spacing as confinement or shear reinforcement at the beams. A high degree of shear reinforcement was used to prevent shear failure of the beam. Reinforcement cages of all specimens are illustrated in Fig. 1.

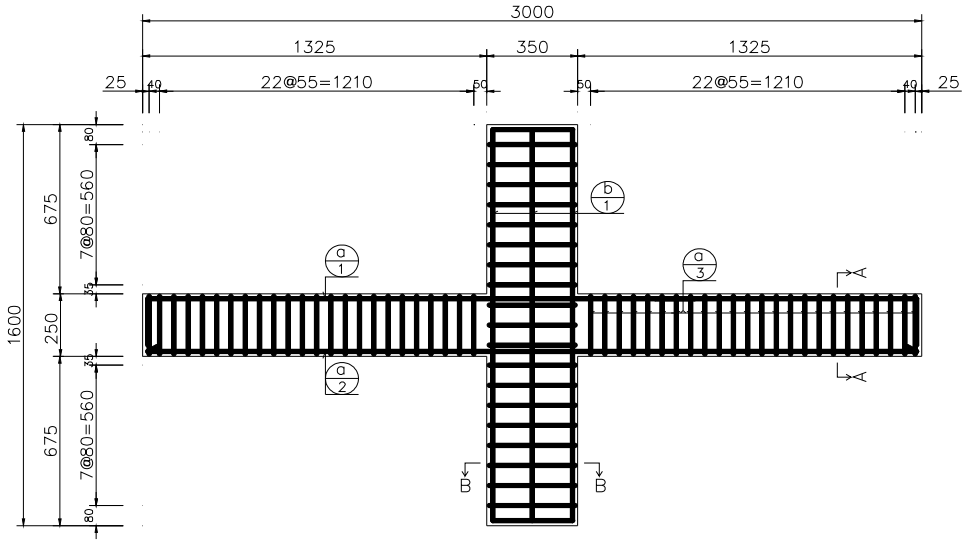

(a)

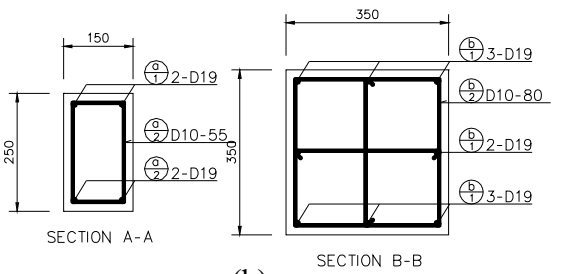

(b)

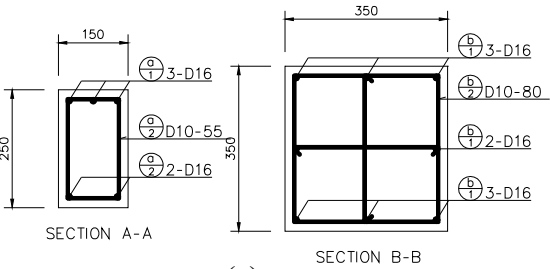

(c)

Fig. 1. Reinforcement detail of all specimens, (a) elevation view of specimen's reinforcing bars, (b) beam and column section for D19-500N specimen, (c) beam and column section for D16-400N and D16-500N specimens. 


\subsection{Instrumentation}

A total of 26 channels were used for measuring the behavior of specimens under reversed cyclic loads. Instrumentation of the specimens focused mainly on the joint region and along the plastic hinge of beams. Drift of the column was measured by 4 Linear Variable Displacement Transformer (LVDT) along the height of the specimen. Rotation and shear deformation of the plastic hinge region was measured by a total of 8 LVDT, as illustrated in Fig. 2.

In the joint region, 14 strain gauges were used for measuring longitudinal and transversal reinforcement. Four strain gauges were placed inside the joint to obtain the bond behavior in this region, and the rest was placed in the plastic hinge region of the beam. A total of 8 strain gauges was attached to the longitudinal reinforcement, and 2 strain gauges measured the transversal reinforcement strain. Measurement of force applied was taken by the internal load cell of the actuator. Measurement taken by LVDT, strain gauges, and load cells were sent to a data logger to be stored in a computer. Reading of all channels was taken every $4 \mathrm{~s}$ second approximately.

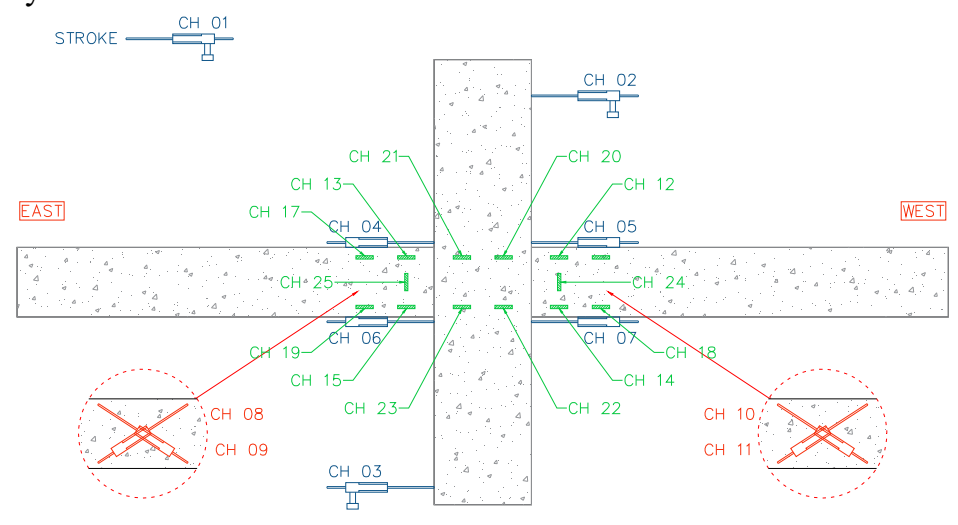

Fig. 2. Instrumentation of the specimen tested.

\subsection{Loading system}

In the experiment, each specimen was given displacement-controlled cyclic lateral loads without axial load to get conservative results. The cyclic lateral loading protocol is defined according to ACI 374.2. Initially, the drift ratio was set to $0.2 \%$ for 3 full cyles. It was then increased to $5.00 \%$ at the end of the loading process. The loading rate ranges from 0.05 to $0.25 \mathrm{~mm} / \mathrm{s}$. The loading protocol is shown in Figure 3 .

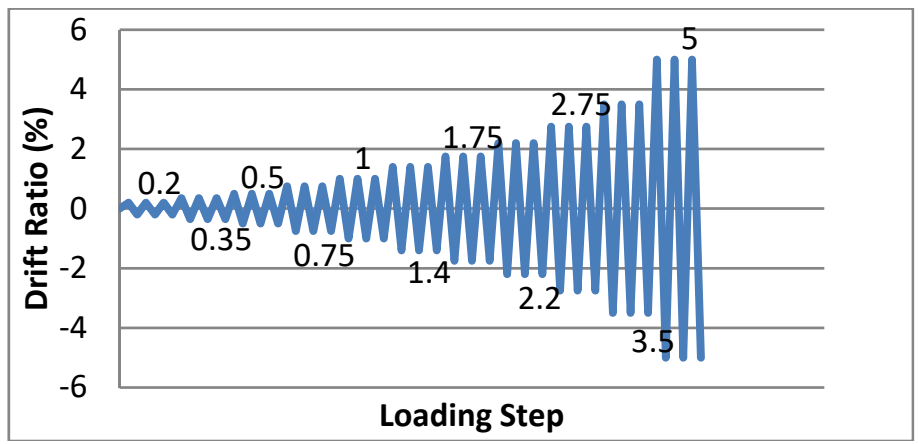

Fig. 3. Loading protocol. 


\subsection{Test setup}

All specimens were used as models for a typical structure system, with the ends of the beams as roller restrains, the bottom of the columns as pin restraints, and the top of the columns were able to move laterally, as shown in Figure 4. Lateral load is applied to the top of the column, displacement-controlled, using $100 \mathrm{kN}$ DARTEC Loading Frame. The test was conducted in the Laboratory of Structure and Building Conctruction, Institut Teknologi Bandung.

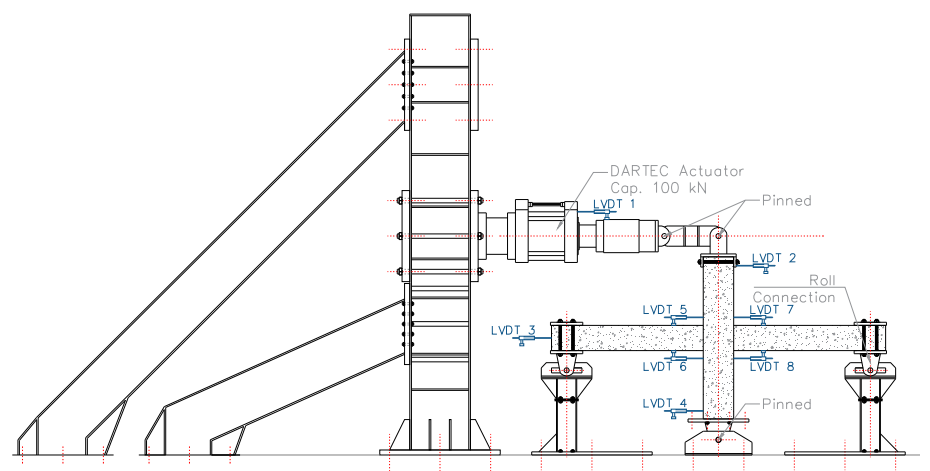

Fig. 4. Test setup.

\section{Experimental results and discussion}

All specimens were subjected to a total of 66 cycles with the drift is increasing from $0.2 \%$ up to $5 \%$. Despite all specimens were heavily damaged at the end of cyclical loading at drift ratio $5 \%$, no failure has observed to occur. Documentary of initial, end, and damage of a sample specimen are shown in Figure 5.

To ensure that the structure element tested is adequate for high seismic risk region, result obtained from laboratory testing then checked against the acceptance criteria explained in ACI 374.1 [7]. Three criteria that must be satisfied, according to the standard, is strength, energy, and stiffness. In this experiment, all the specimens pass the criterion for all the standard from ACI 374.1. 

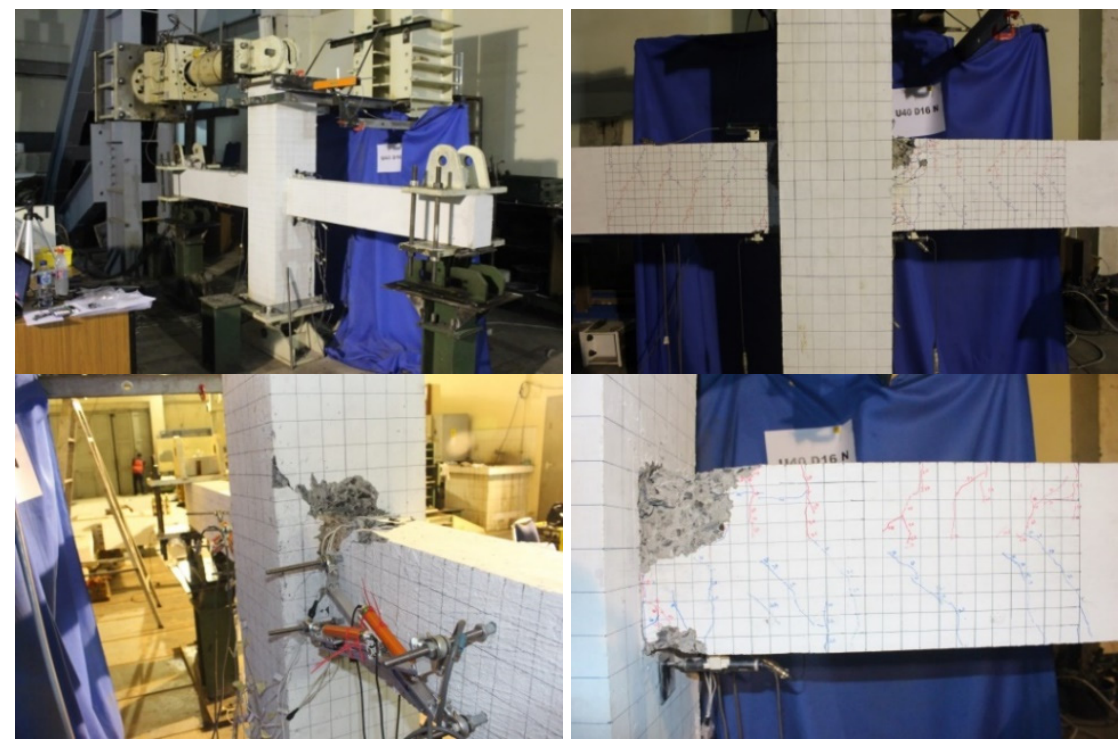

Fig. 5. Documentary of initial, end, and damage of a specimen.

\subsection{Hysteretic curves}

The hysteretic curves, which represent the response of the specimens to drift-controlled lateral loads, are shown in Figure 6. Important events are recorded, such as first crack, significant yield, and spalling of the specimens, and they were compared in Table 3. First crack was observed to happen in the specimens at the same drift level, which was approximately at $0.35 \%$ drift. It should also be noted that spalling happened in all the specimens, it occured at 2.2\% drift for D16-400N, $2.7 \%$ for D16-500N, and 3.45\% for D19$500 \mathrm{~N}$.
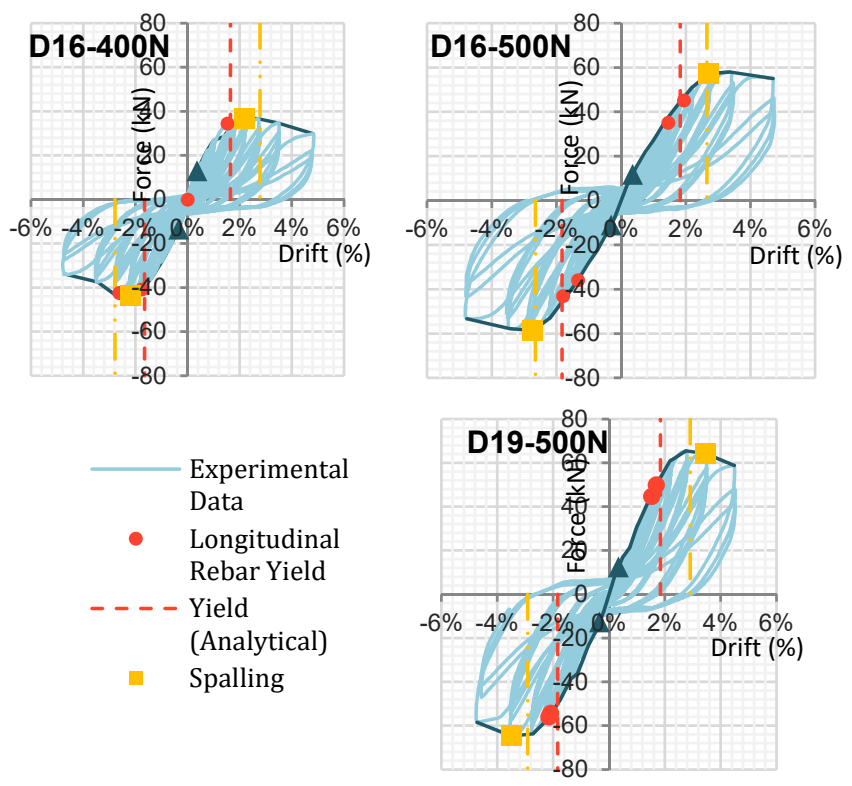

Fig. 6. Comparison of experimental hysteretic curves for all specimen. 
Table 3. Summary of test events for all specimens.

\begin{tabular}{|c|r|r|r|r|r|r|}
\hline \multirow{2}{*}{ Specimens } & \multicolumn{2}{|c|}{ First Crack } & \multicolumn{2}{c|}{ Significant Yield } & \multicolumn{2}{c|}{ Spalling } \\
\cline { 2 - 7 } & $\begin{array}{c}\text { Drift } \\
\mathbf{( \% )}\end{array}$ & $\begin{array}{c}\text { Force } \\
\mathbf{( k N )}\end{array}$ & \multicolumn{1}{c|}{ Drift (\%) } & Force (kN) & Drift (\%) & Force (kN) \\
\hline \multirow{2}{*}{ D16-400N } & $0.353 \%$ & 12.996 & $1.627 \%$ & 36.483 & $2.182 \%$ & 36.843 \\
\cline { 2 - 7 } & $-0.350 \%$ & -13.526 & $-1.762 \%$ & -40.779 & $-2.194 \%$ & -43.346 \\
\hline \multirow{2}{*}{ D16-500N } & $0.350 \%$ & 11.808 & $1.934 \%$ & 45.164 & $2.703 \%$ & 57.222 \\
\cline { 2 - 7 } & $-0.313 \%$ & -11.038 & $-1.806 \%$ & -43.066 & $-2.733 \%$ & -58.621 \\
\hline \multirow{2}{*}{ D19-500N } & $0.341 \%$ & 12.506 & $1.535 \%$ & 44.586 & $3.451 \%$ & 64.286 \\
\cline { 2 - 7 } & $-0.340 \%$ & -12.645 & $-2.088 \%$ & -54.384 & $-3.485 \%$ & -64.704 \\
\hline
\end{tabular}

\subsection{Backbone curve}

First cycle of each drift level is connected forming the backbone curve of specimens. Comparisons of the backbone curve for all specimens are shown in Figure 7.

From the backbone graphs comparison, substitution of conventional $420 \mathrm{MPa}$ to $520 \mathrm{MPa}$ rebar gives a significant improvement in lateral load capacity. Peak lateral load capacity of higher strength rebar specimens increased by about $35.18 \%$ over the control specimen as expected. Yield strength increase of rebar was not compensated by the reduction of the rebar area in both the beam and column section. An exact value of the peak lateral load can be found in Table 4.

Table 4. Peak load comparison of backbone curves for all specimens.

\begin{tabular}{|c|c|c|}
\hline \multirow{2}{*}{ Specimens } & \multicolumn{2}{|c|}{ Ultimate Force (kN) } \\
\cline { 2 - 3 } & $(+)$ dir. & $(-)$ dir. \\
\hline D16-400N & 43.346 & 36.843 \\
\hline D16-500N & 58.621 & 57.991 \\
\hline D19-500N & 64.704 & 65.555 \\
\hline
\end{tabular}

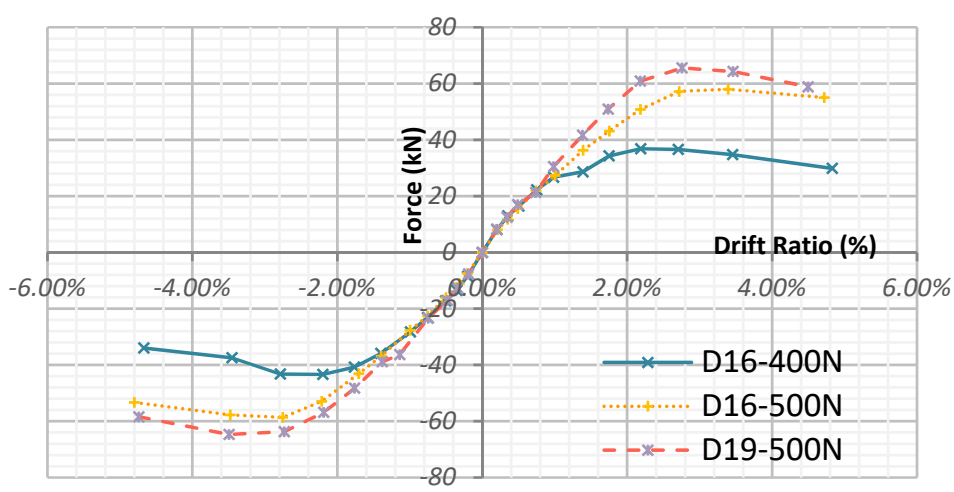

Fig. 7. Force-Drift backbone curve comparison.

\subsection{Energy dissipation}

Energy dissipation values were determined continuosly until the end of loading, i.e, at $5.00 \%$ drift ratio. The results showed that the energy dissipation increased along with increasing drift ratio. In this study, energy dissipation values were normalized by the significant yield (Table 3 ) to show the effect of different reinforcing strengths for energy dissipation. 
The normalized cumulative energy dissipation values for each drift ratio and cycle are shown in Figure 8. The values of normalized cumulative energy dissipation indicate that specimens with higher strength reinforcement is relatively the same with lower strength, but lower strength reinforcement have a higher displacement ratio.

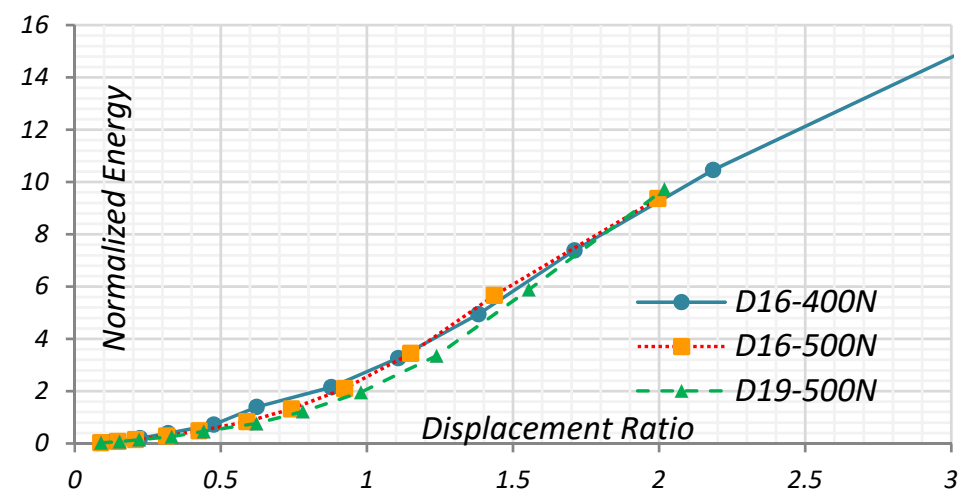

Fig. 8. Normalized cumulative energy.

\subsection{Deformability}

Deformability is determined as the ratio of the ultimate deformation to the limit deformation [8]. According to ASCE 7.10, ultimate deformation is the deformation at which failure occurs and that shall be deemed to occur if the sustainable load reduces to 80 percent or less of the maximum strength, and limit deformation is two times the initial deformation that occurs at a load equal to 40 percent of the maximum strength. The deformability values (Table 5) show that specimens with a high strength reinforcing bars have smaller deformability than the specimen with normal strength reinforcing bars.

Table 5 Deformability.

\begin{tabular}{|c|c|c|c|c|}
\hline Specimen & $\begin{array}{c}\boldsymbol{\delta}_{\text {limit }} \\
(\mathbf{m m})\end{array}$ & $\begin{array}{c}\text { סultimit } \\
(\mathbf{m m})\end{array}$ & Deformability & Remark \\
\hline D16-400N & 16.689 & 83.045 & 4.976 & High \\
\hline D16-500N & 28.361 & 133.828 & 4.719 & High \\
\hline D19-500N & 29.989 & 104.157 & 3.473 & Limited \\
\hline
\end{tabular}

\subsection{Peak to peak stiffness}

Stiffness was determined as the gradient of the peak to peak of hysteretic curve at every cycle. Stiffness values for every cycle was then normalized by the initial stiffnes of all specimens. In this experiment, specimen D16-400N had peak to peak initial stiffness higher than the other two specimens. Normalized stiffnes shown in Figure 9 indicate that specimens with high strength reinforcing bars tends to have slightly smaller stiffness degradation. 


\section{Stiffness (Peak-to-Peak, Normalized by Initial Stiffness)}

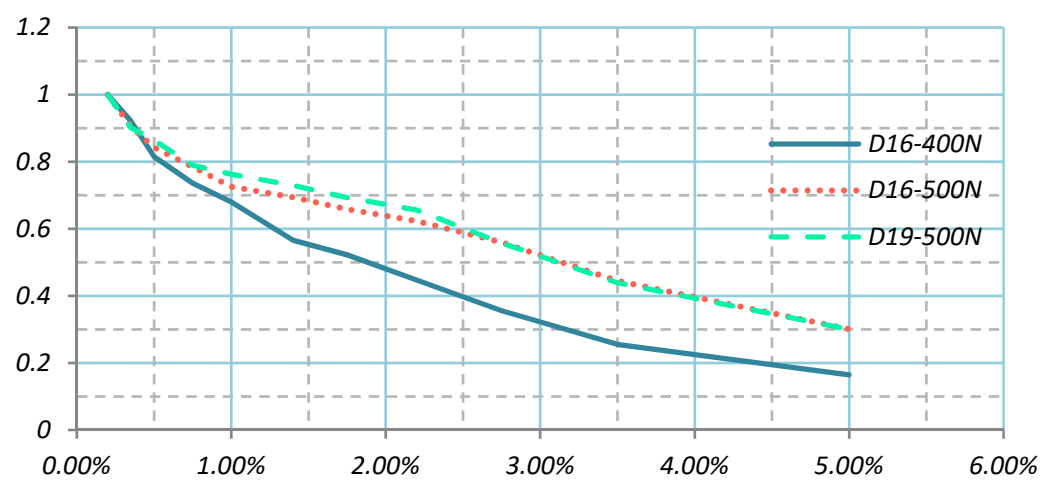

Fig. 9. Stiffness degradation.

\section{Conclusions}

Three specimens, half-scaled models, were tested with the variation of diameter and yield strength reinforcement bars used. One of them used normal strength reinforcing bars and the other two were used high strength reinforcing bars. All specimens were subjected to identical cyclic loading to make a comparative study. Interpretation of the data obtained from the testing is as follows:

- Specimens with normal strength reinforcing bars (D16-400N) had larger normalized energy dissipation than specimens with high strength reinforcing bars (D16-500N and D19-500N) but the difference is not significant.

- Specimen D16-400N had deformability values 4.976 (high-deformability element), Specimen D16-500N had deformability values 4.719 (high-deformability element), and specimen D19-500N had deformability values 3.473 (limited-deformability element). It was indicated that specimens with high strength reinforcing bars tend to have smaller deformability than that of specimen with normal strength reinforcing bars.

- At 3.50\% drift ratio, specimen D16-400N, D16-500N and D19-500N had stiffness degradation $74.46 \%, 55.5 \%$ and $55.3 \%$ from each initial stiffness respectively. At $5 \%$ drift ratio, specimen D16-400N, D16-500N and D19-500N had stiffness degradation $83.56 \%, 69.9 \%$ and $69.8 \%$ from each initial stiffness respectively. It was indicated that specimens with high strength reinforcing bars tend to have smaller stiffness degradation than normal strength reinforcing bars.

- From this experiment, we can conclude that high-strength reinforcing bars can be used as an alternative for earthquake resistance building, because normalized energy dissipation of high-strength reinforcing bars is relatively the same with that of normal strength reinforcing bars. However, high-strength reinforcing bars have smaller deformability than that of normal strength reinforcing bars, so we need to check the deformability to utilize high strength reinforcing bars.

\section{References}

1. A. Retika, I. Imran, Perilaku Lekatan Baja Tulangan U-50 Tempcore Terhadap Beban Monotonik dan Siklik, Seminar HAKI, Jakarta (2010) 
2. I. Imran, A. Retika, R. Soegiarso, Mechanical Characteristics of Steel Rebars Available in Indonesia Industries, (Proceedings of the 11th EASEC, NTU, 2008)

3. ACI Committee 374, ACI 374.2 Guide for Testing Reinforced Concrete Structural Elements Under Slowly Applied Simulated Seismic Loads (Farmington Hills: American Concrete Institute, 2013)

4. ASTM Committee A615/A615M, Standard Specification for Deformed and Plain Carbon-Steel Bars for Concrete Reinforcement (AASHTO, 2015)

5. Badan Standardisasi Nasional, SNI 2052:2017 Baja Tulangan Beton (Badan Standardisasi Nasional, Jakarta, 2017)

6. Badan Standardisasi Nasional, SNI 2847:2013 Persyaratan Beton Struktural untuk Bangunan Gedung (Badan Standardisasi Nasional, Jakarta, 2013)

7. ACI Committee 374, ACI 374.1 Acceptance Criteria for Moment Frames Based on Structural testing and Commentary (Farmington Hills: American Concrete Institute, 2005)

8. American Society of Civil Engineers, ASCE 7.10 Minimum Design Loads for Buildings and Other Structures (Virginia, 2010) 